\title{
Evaluating Student Confidence in Engineering Design, Teamwork and Communication
}

\author{
Ann F. McKenna ${ }^{1}$, Penny Hirsch ${ }^{2}$ \\ Robert R. McCormick School of Engineering and Applied Science ${ }^{1} /$ The Writing Program $^{2}$, \\ Northwestern University
}

\begin{abstract}
Many researchers have focused on the role of confidence and motivation on learning and have suggested that students be encouraged to engage in reflection about the role of their selfperceptions in achievement. In this paper we explore how students' confidence levels change during our freshman engineering design program. During the 2003-2004 academic year we implemented a survey designed to measure students' confidence in design problem-solving abilities and associated teamwork and communication skills in Northwestern University's first year Engineering Design and Communication (EDC) course. Analyses of the survey data show significant gains in students' confidence to apply specific design, communication, and teamwork skills. Results from our study provide valuable information about our students, and one perspective for evaluating the effectiveness of design-focused learning environments.
\end{abstract}

\section{Introduction}

Many factors need to be considered when creating and evaluating learning environments that support design problem-solving. Learning environments include inanimate features such as the classroom setting, course materials like textbooks, multimedia documents or other learning tools, and specific assignments that need to be completed. To inform the design of these features one could refer to instructional frameworks such as the How People Learn (HPL) framework to guide effective design of course activities ${ }^{1}$. For example, the HPL framework suggests that a learning environment be assessment-centered so that student understanding is monitored throughout the course, and appropriate and timely feedback is given to correct any misunderstanding. Using this HPL principle one could design assessment tools or course assignments to achieve this goal.

In addition to these inanimate features, learning environments also include people, specifically students and instructors. This humanistic element introduces additional factors to be considered when designing and evaluating learning environments. For example, students and instructors bring certain beliefs and expectations about the course and subject matter. These beliefs and expectations influence the approach one takes to learning and teaching. Motivation also plays an essential role in how much time and effort one devotes to learning and teaching the subject matter. These humanistic elements offer an additional perspective for evaluating the effectiveness of courses. In this paper, we focus on one humanistic element, namely students' 
confidence, how that element can be related to the learning goals of EDC, and whether our freshman design course increases students' confidence.

Many researchers have focused on the role of confidence and motivation on learning. For example, Hynd and coworkers explain that persistence and effort are outcomes of motivating influences such as "self efficacy, interest, a desire for good grades and a belief that the information is relevant and useful" (p. 55) ${ }^{2}$. Hynd and coworkers argue that, in order to support learning at the conceptual change level, students should be encouraged to engage in reflection about the role of their self-perceptions in achievement. This type of reflection is embedded in our assessment approach by asking to students to evaluate their confidence along specific performance criteria.

Furthermore, Keller has developed the ARCS model of motivation that provides a framework for understanding the major influences on the motivation to learn ${ }^{3}$. The ARCS model defines four major conditions that need to be met for people to become and remain motivated: attention, relevance, confidence, and satisfaction. As Keller explains, confidence "can influence a student's persistence and accomplishment" (p. 5) ${ }^{3}$. Therefore, this motivating influence can affect the overall performance level in students. In this paper we focus on the confidence dimension of the model and explore how students' confidence levels change during our freshman engineering design program. Results from our study provide valuable information about our students, and one perspective for evaluating the effectiveness of our freshman program, EDC.

\section{Background on Engineering Design and Communication}

Engineering Design and Communication (EDC) is a required course for all engineering students at Northwestern. EDC is designed and taught by faculty from both the engineering school and the university's Writing Program. In EDC, students work in small teams to tackle real-world design problems brought to them by individuals, not-for-profit organizations, entrepreneurs and industry. Students learn about the design process, about written, spoken, and graphical communication, and about teamwork and collaboration ${ }^{4}$.

Since all of the EDC design projects are actual design problems with real clients and users, the course also addresses the "relevance" condition of the ARCS model. Students consult with clients to define the project goals, meet with users to get feedback on different design ideas, and ultimately create solutions (often working prototypes) that are given to the client to be implemented and used. Through these authentic design activities students see first-hand the impact of their design solutions, and the relevance of their work in a broader context. In Keller's discussion of relevance he poses the question, "How many times have we heard students ask, "Why do I have to study this?"” (p. 3). We do not hear this question in EDC.

The following two examples of design projects provide some context for our study. Both come from winter quarter 2004. All projects that quarter were focused on assistive technologies or sports equipment for the disabled. For example, one project, the "doorknob locking system", was to create a system that allows a person to unlock and open the door at the same time with one hand. This type of device is necessary for individuals who have had a stroke and are unable to perform bilateral tasks, or have limited or no use of one upper extremity. Another project, the 
"rickshaw exerciser", involved designing a system for athletes with disabilities to independently vary resistance on a rickshaw exerciser. This is important for individuals with higher spinal cord injuries (which result in upper extremity disability) so they can independently add weight plates to the machine.

We provide these examples to demonstrate that there is a broad community context to the EDC student design work, and therefore, relevance to the outside world is embedded in the projects. However, this is only one interpretation of relevance. Keller states, "Relevance does not have to come from the content itself" (p. 3). He explains that the condition of relevance can be met in terms of satisfying one's intellectual curiosity and learning needs. In this way, the subject matter itself, independent of a direct application, could be perceived as relevant, and as a result motivating. This is an interesting extension of how relevance is often described in engineering education. That is, there are other factors that make learning relevant, independent of whether or not there is an immediate and direct application of the subject matter. While this paper focuses on the confidence condition of the ARCS model, future work will further explore the variations of how learners perceive relevance.

\section{Method}

We implemented a survey that contained 26 forced-choice items where students rated their confidence level in performing various design, communication, and teamwork abilities (see Table 1 for all 26 items). The survey is a modified version of one used by Atman et al. at the University of Washington in their freshman design course ${ }^{5}$. As Atman and co-workers explain, the validity and utility of the instrument to describe changes in students' attitudes about engineering, and perceptions of their abilities, have been established by previous studies ${ }^{6,7}$. Students rated their confidence level on a 1-6 point scale. The purpose of these 26 items was to provide insight into students' confidence in their knowledge and skills, and how these perceptions might have changed as a result of EDC.

Each of the items is related to the goals of the course as well as the activities students completed as part of their design project work. Each item begins with a verb that is associated with a particular cognitive level as described in Bloom's taxonomy. According to Bloom, the cognitive domain encompasses a complex, hierarchical series of intellectual skills involving the acquisition and use of knowledge that ranges from simple recall to the ability to judge and evaluate learned material ${ }^{8}$. Survey items were constructed to represent all six levels of the taxonomy. We used Bloom's taxonomy as a framework to make the item wording consistent, and to group items according to particular cognitive levels.

We administered the survey at the beginning and at the end of the course. Since EDC is a twoquarter sequence, this means that students completed the survey during the first week of winter quarter and again during the last week of spring quarter. Students were asked to complete the survey on-line as part of the course deliverables. Students did not receive a grade or credit for completing the survey; we had an approximately $79 \%$ response rate for the pre survey and an approximately $47 \%$ response rate for the post survey. 


\begin{tabular}{|c|c|c|c|}
\hline Survey Items & Pre Avg. & Post Avg. & Effect Size \\
\hline 1) Define the problem clearly and precisely. & 4.2 & 5.1 & 0.9 \\
\hline $\begin{array}{l}\text { 2) Identify the knowledge and the sources of information needed to } \\
\text { understand the problem. }\end{array}$ & 3.9 & 5.1 & 1.2 \\
\hline 3) Generate criteria for evaluating the quality of a solution. & 3.9 & 4.9 & 0.8 \\
\hline 4) Breakdown a problem into manageable components or tasks. & 3.8 & 5.2 & 1.3 \\
\hline 5) Identify all needs to be addressed by the design problem. & 4.1 & 4.95 & 0.9 \\
\hline $\begin{array}{l}\text { 6) Make effective oral presentations, using PowerPoint, to } \\
\text { communicate design concepts and/or solutions. }\end{array}$ & 3.9 & 4.9 & 1.1 \\
\hline $\begin{array}{l}\text { 7) Create strategies for monitoring and evaluating problem-solving } \\
\text { progress. }\end{array}$ & 3.6 & 4.8 & 1.1 \\
\hline 8) Generate possible alternative solutions. & 3.8 & 5.0 & 1.2 \\
\hline $\begin{array}{l}\text { 9) Select an existing mathematical model that can be used to } \\
\text { characterize a solution. }\end{array}$ & 3.4 & 4.3 & 0.8 \\
\hline 10) Identify the pros and cons of possible solutions. & 4.4 & 5.4 & 1.1 \\
\hline 11) Create sketches to communicate design concepts. & 3.6 & 4.9 & 1.0 \\
\hline $\begin{array}{l}\text { 12) Evaluate different design solutions using a specified set of } \\
\text { criteria. }\end{array}$ & 3.9 & 5.1 & 1.3 \\
\hline 13) Conduct brainstorming sessions to explore possible solutions. & 4.1 & 5.2 & 1.1 \\
\hline 14) Prepare Gantt and RAM charts to manage project. & 1.7 & 5.0 & 3.1 \\
\hline 15) Analyze which solution best satisfies the problem objectives. & 4.0 & 5.1 & 1.1 \\
\hline 16) Build a prototype or final solution. & 3.4 & 5.0 & 1.4 \\
\hline 17) Document my process of obtaining a solution. & 3.6 & 4.9 & 1.2 \\
\hline 18) Monitor team progress to ensure goals are being met. & 4.0 & 4.9 & 0.8 \\
\hline $\begin{array}{l}\text { 19) Compose text, tables, or graphs to communicate design } \\
\text { solution(s). }\end{array}$ & 4.2 & 5.1 & 0.8 \\
\hline $\begin{array}{l}\text { 20) Recognize when changes to the original understanding of the } \\
\text { problem may be necessary. }\end{array}$ & 3.8 & 5.0 & 1.2 \\
\hline $\begin{array}{l}\text { 21) Justify making modifications or improvements to a final } \\
\text { solution. }\end{array}$ & 4.1 & 5.2 & 1.2 \\
\hline $\begin{array}{l}\text { 22) Explain the different roles and responsibilities of being an } \\
\text { effective member in a team. }\end{array}$ & 4.2 & 5.1 & 0.9 \\
\hline 23) Create detail drawings of design solutions. & 3.2 & 4.7 & 1.1 \\
\hline 24) Resolve conflict and reach agreement in a group. & 4.1 & 4.9 & 0.7 \\
\hline 25) Persuade others to accept my design. & 4.0 & 5.0 & 0.9 \\
\hline $\begin{array}{l}\text { 26) Communicate effectively with clients, teammates and } \\
\text { supervisors. }\end{array}$ & 4.3 & 5.2 & 0.8 \\
\hline
\end{tabular}

Table 1. Average pre and post scores and effect sizes for items.

We conducted a matched pair analysis on the survey data so our data set includes only those students who completed both the pre and post survey. After eliminating post responses that did not have a matching pre, the response rate was approximately $43 \%(\mathrm{~N}=145)$. In order to determine if this is a representative sample of the total class, we compared demographic data of the sample to the entire EDC class. We compared GPA, gender and ethnicity. There were no significant differences between the average GPA of the sample and the entire class, $t(332)=$ $0.917, \mathrm{p}=0.36$. In addition, the data given in Table 2 indicate that those who completed the survey are representative of the entire class with respect to gender and ethnicity. 


\begin{tabular}{|l|c|c|}
\hline & Those who Completed Survey & Entire EDC Class \\
\hline Male & $71 \%$ & $72.4 \%$ \\
\hline Female & $29 \%$ & $27.6 \%$ \\
\hline Black & $3.6 \%$ & $3.3 \%$ \\
\hline Asian-Amer. & $22.6 \%$ & $20.9 \%$ \\
\hline Mex.-Amer. & $3.6 \%$ & $4.2 \%$ \\
\hline Foreign & $9.5 \%$ & $13.6 \%$ \\
\hline White & $51.1 \%$ & $48.2 \%$ \\
\hline Unknown & $9.5 \%$ & $9.7 \%$ \\
\hline
\end{tabular}

Table 2. Demographic data for those who completed survey as well as for the entire class.

\section{Results and Discussion}

We performed statistical analyses on average pre and post survey scores and found significant differences* for all 26 items. These results indicate that students' confidence level significantly increased for a wide range of design, teamwork, and communication abilities. For reporting purposes we grouped the items into five categories: 1) define/understand the problem, 2) generate/evaluate solutions, 3) manage the process, 4) teamwork, and 5) communication. Grouping items enables us to display the data in a systematic format. The grouping is not meant to suggest that any one item is specific to only that one category. Due to space considerations, and for the sake of brevity, we focus on the results only from categories 2, 3, and 5. Similar results were found for categories 1 and 4 .

Figure 1 shows the pre and post average ratings for three items in the category generate/evaluate solutions. Items included in this category relate to generating alternatives, developing criteria to evaluate alternatives, and performing techniques to explore alternatives such as prototyping and mathematical modeling. As mentioned previously students' confidence level significantly increased on each of these items. We note that items 16, 12, and 8 showed the highest effect sizes of $1.4,1.3$, and 1.2 respectively (see Table 1$)^{+}$. Item 16 asks students to rate their confidence in building a prototype or final solution. On average students enter with "fair" confidence and this increases to "very good" confidence after the course. This is an encouraging result for two reasons. First, we would expect that, in general, freshman students are not familiar with prototyping and its role in the design process. Since the pre result average is small (3.4 out of 6), it suggests that our expectation is accurate and that students are completing the survey honestly. This contributes to the validity of the results. Second, there is an expressed focus in EDC to develop students' hands-on ability. Students are required to build and test mockups of design alternatives, complete machine shop training, and develop working prototypes of design solutions (depending on the nature of the design problem). Significant gains and large effect sizes indicate that these activities contribute to increasing students' confidence in hands-on activities. This is a positive result for the EDC course.

\footnotetext{
${ }^{*}$ All items significant at $\mathrm{p}<.001$ level.

${ }^{+}$Conventional effect size values state that $0.2=$ small effect, $0.5=$ medium effect, $0.8=$ large effect 


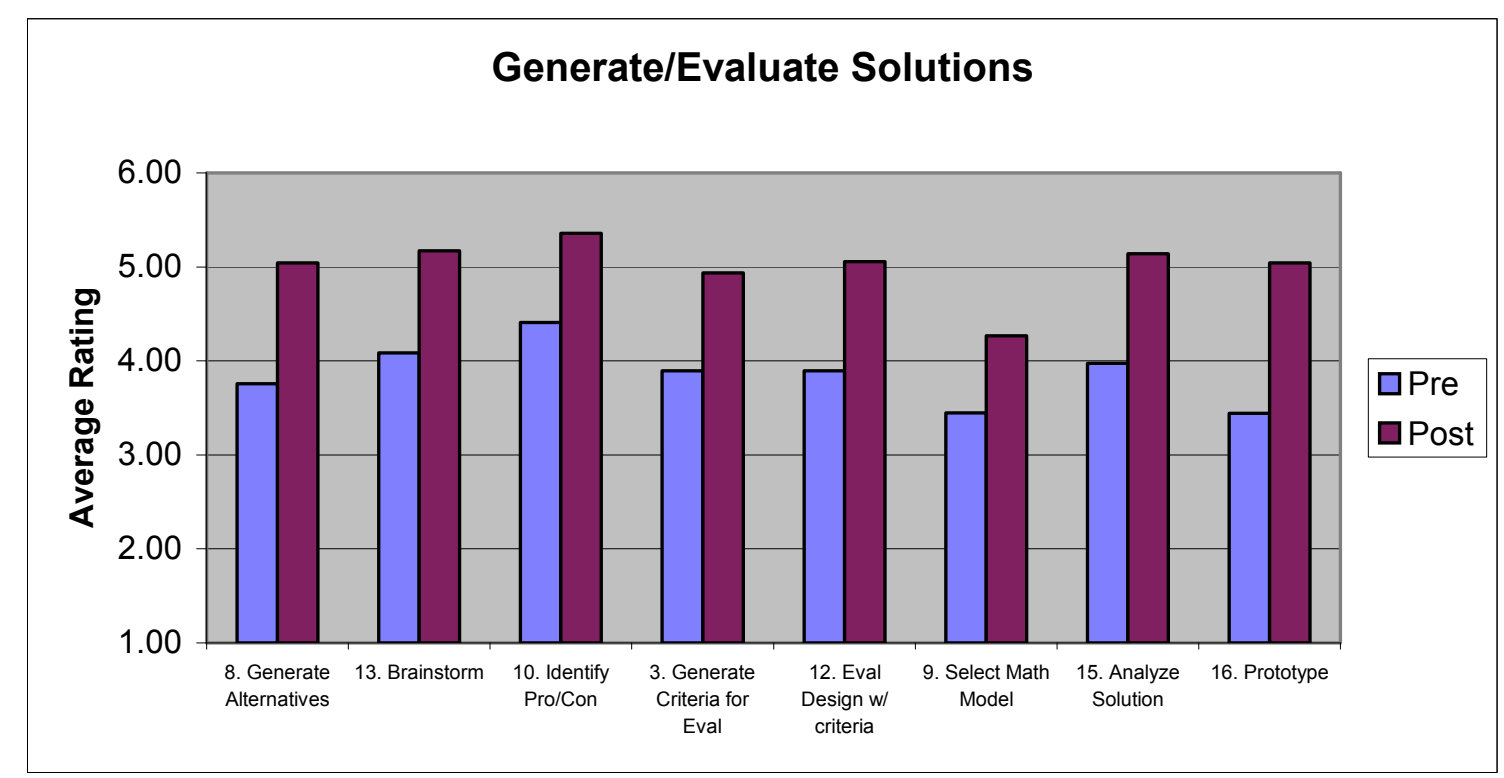

Figure 1. Average pre and post ratings for items in category generate/evaluate solutions.

It is also interesting to note the large effect sizes on item 8: Generate possible alternative solutions and 12: Evaluate different design solutions using a specified set of criteria. Significant gains on these two items suggest that EDC contributes to two primary objectives. Specifically, EDC intends to convey to students that there are multiple solution paths to solving a design problem. The course emphasizes exploring several alternatives through brainstorming exercises, consulting with peers, users, and experts, and conducting research into model and competitive products. Design teams are coached to generate alternatives not only in the beginning of the project but also throughout the entire design process.

In addition, students use several methods to help them make sense of their design alternatives such as clustering design ideas, constructing alternatives matrices, building and testing mockups, and establishing requirements and specifications. These activities are intended to convey to students that, while design problems are open-ended and initially ill defined, design problem solving is a structured and analytical process. Results to item 12 suggest that EDC contributes to students' awareness of an analytical approach, using specified criteria, to evaluate design solutions.

The other items in the category generate/evaluate solutions also show significant gains and large effect sizes. Each of these items describes activities associated with generating alternatives and evaluating design solutions such as brainstorming, identifying pros/cons, and generating criteria. However, we note the results for item 9: Select an existing mathematical model that can be used to characterize a solution. This item received the lowest post rating (4.3) of all 26 items. Even though the gain is significant, students' confidence on this item changed only from "fair" to "good". This result is consistent with previous data and is not surprising given the focus of EDC. In EDC students are not expected to perform mathematical modeling of design solutions; the emphasis is on understanding and using design process to solve problems. We recognize this gap in EDC but do not necessarily see this as a weakness. Rather, EDC builds a foundation for 
freshman engineering students in rigorous design process. As students advance in the curriculum, and gain a deeper understanding of engineering analysis, they can bring these computational skills into the foundation established in EDC.

Figure 2 displays the pre and post average ratings for items in the category manage process. Items in this category include the use of tools such as Gantt charts and problem-solving techniques such as breaking down the problem and creating strategies for monitoring progress. Item 14: Prepare Gantt and RAM charts to manage project immediately stands out as having the largest gain with a very large effect size of 3.1. Similar to prototyping we would expect that, in general, freshman students are not familiar with Gantt and RAM charts. The pre average on this item indicates students have little (to no) confidence in preparing Gantt and RAM charts to manage the project. Again, this result suggests that our expectation is accurate and that students are completing the survey honestly.

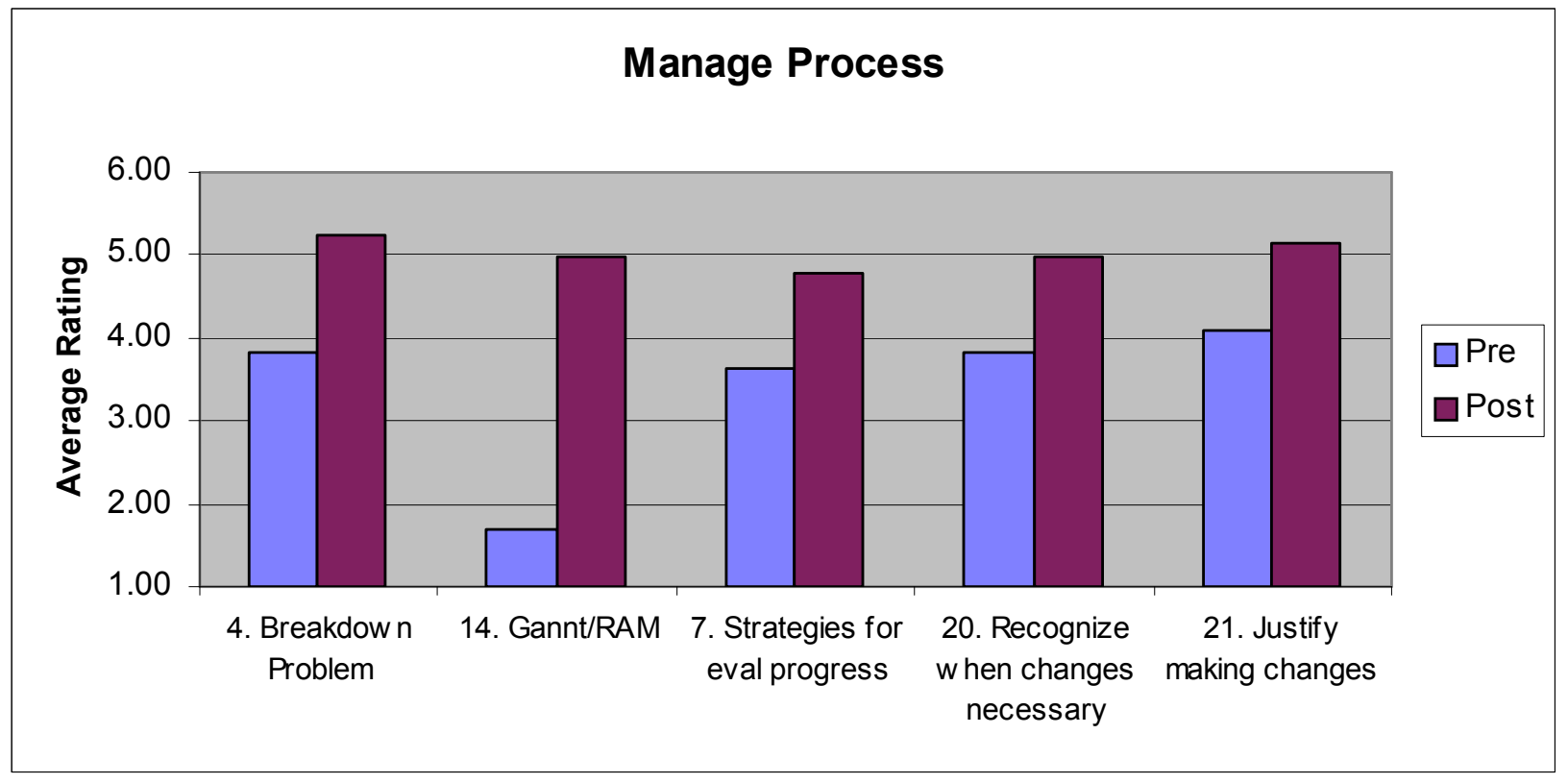

Figure 2. Average pre and post ratings for items in category manage process.

Item 4: Breakdown a problem into manageable components or tasks also resulted in a large effect, 1.3. Average ratings increased from "fair/good" to "very good". This item is related to EDC's goal of conveying design problem-solving as a structured and analytical process. Breaking down a problem into parts is a common strategy for managing any type of complex problem. Results indicate that EDC is increasing students' awareness and confidence in this area.

Figure 3 displays the pre and post average ratings for items in the category communication. Items in this category include oral, written and graphical communication. A couple of results are notable. First, the largest effect is on item 17: Document my process of obtaining a solution. In EDC we instruct students to do specific things in documenting the process. These include writing a mission statement, identifying constraints, defining user and stakeholder needs, defining specifications, as well as using appropriate formatting. 




Figure 3. Average pre and post ratings for items in category communication.

Another interesting result is students' high pre rating on items 25 and 26. Students enter with "good" confidence in their ability to persuade others to accept their design, and to communicate effectively with clients, teammates and supervisors. It would be interesting to explore how students define persuasion and effective communication, and what they think is involved in performing these abilities. Even though the ratings may appear high, they may be internally consistent with students' notions of what it means to persuade and communicate, but inconsistent with faculty notions of persuasion and effective communication. Exploring these questions in more detail would uncover students' initial and post understanding and could better determine how they align or disconnect with the goals of EDC.

The survey also contained three items that asked students to rate the likelihood of pursuing a degree in engineering, completing the requirements of an engineering degree, and confidence that engineering is the right career choice. Students rated these items on a scale of 1-5. Figure 4 shows the pre and post results for these items. From fig. 4 we see that students rated these items consistently and almost identically between pre and post. Students rate the likelihood of pursuing and completing the requirements of an engineering degree "high" to "very high". These ratings are consistent with Northwestern's overall retention data. One way to measure retention is to determine those students who persist in engineering from freshman to sophomore year. Of those engineering students who entered Northwestern as freshman in $2003,87 \%$ have persisted in engineering into the sophomore year.

Finally, on average students are "moderately confident" that engineering is the right career choice. Since the average ratings were the same both pre and post, we interpret these findings to indicate that the first year engineering curriculum does not interfere with students' already high confidence in their choice of engineering as a career path. 


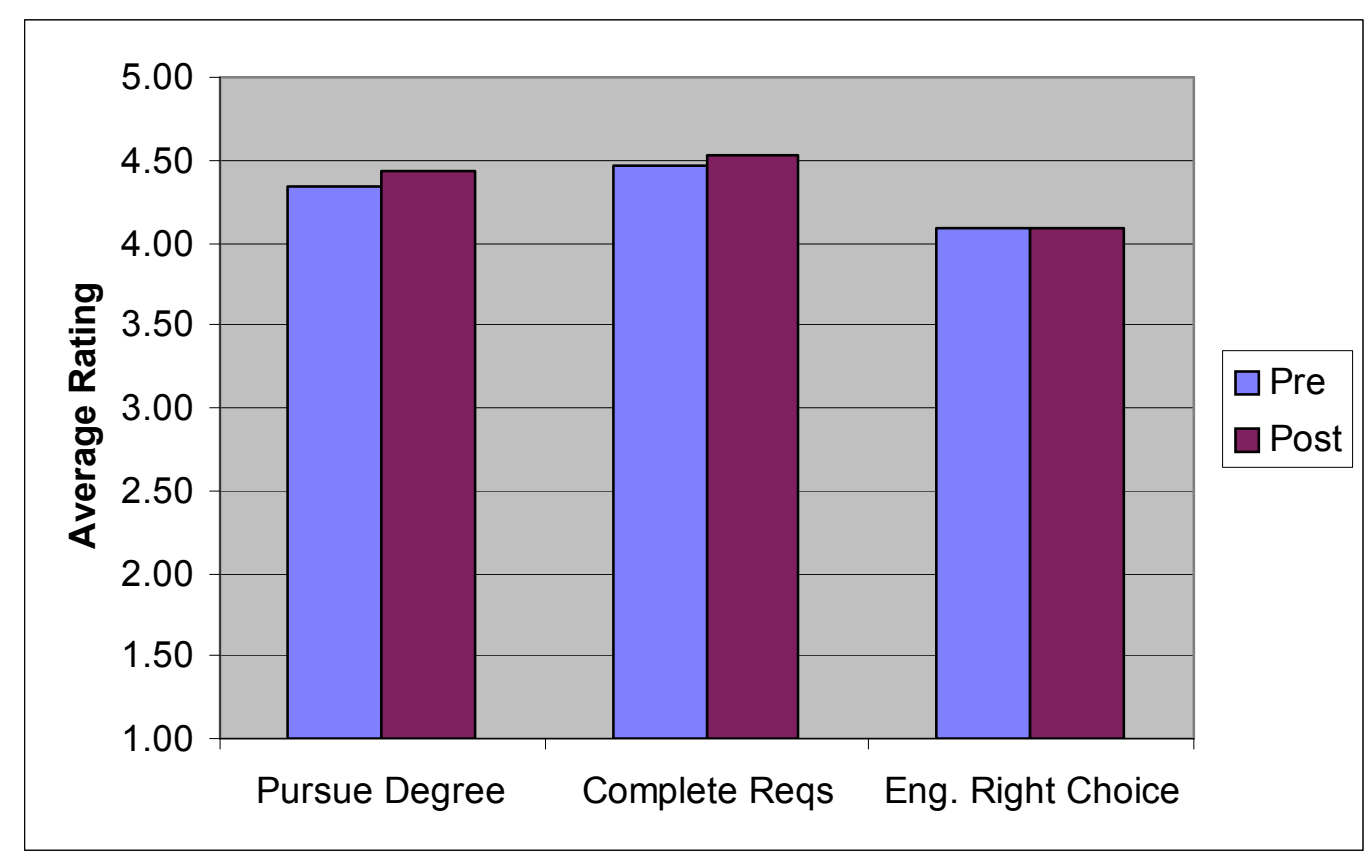

Figure 4. Pre and post average ratings for items that ask students the likelihood of pursuing and completing an engineering degree, and that engineering is the right career choice.

\section{Summary and Next Steps}

During the 2003-2004 academic year we implemented a survey designed to measure students' confidence in design problem-solving abilities and associated teamwork and communication skills in Northwestern University's first year Engineering Design and Communication (EDC) course. Analysis of the survey data showed significant gains in students' confidence to implement specific design, communication, and teamwork skills.

The survey contained 26 items that asked students to rate their confidence on a variety of skills related to design, teamwork and communication. Results indicate significant gains in students' confidence to perform design activities such as building prototypes, communication activities such as creating sketches to communicate design concepts, and teamwork skills such as resolving conflict and reaching agreement. These results suggest that the learning environment of EDC contributes to students' awareness of, and confidence in, the central learning goals of EDC. These results relate to the confidence component of Keller's ARCS model of instructional design and suggest that EDC creates a learning environment that develops students' confidence, a major condition that can affect the overall performance level in students. Future work will explore the other conditions in the ARCS model (attention, relevance, and satisfaction) to provide a more comprehensive understanding of the motivational factors that affect design learning.

Finally, students enter with high ratings of their likelihood of pursuing an engineering degree, completing the degree requirements, and confidence that engineering is the right career choice. These ratings remain high after the end of the first year so these results suggest the curriculum reinforces students' initial confidence in their ability to pursue and complete the curriculum. 
Our results have implications for others who teach engineering design courses. Pedagogical factors that may help account for the students' growth in confidence may be that we repeat the process twice, with different projects each quarter. Students also receive continuous feedback from professors, clients, and users on their project work. Each section contains a maximum of 16 students (4 teams), and is co-taught by two faculty: one from the engineering school and one from the university's Writing Program. This course structure emphasizes a highly collaborative and iterative process for both design and communication.

\section{Acknowledgements}

We would like to thank the students in the EDC program for participating in our study. We also thank several EDC faculty for their useful feedback on the survey, and assistance in implementing the survey. Specifically, we thank John Anderson for his technical support with the on-line survey, and Barbara Shwom for her careful review of the survey items.

\section{References}

1. Bransford, J. D., Brown, A. L., and Cocking, R. R. (Eds.) (2000). How people learn: Brain, mind, experience, and school. Washington, DC: National Academy Press.

2. Hynd, Cynthia, Holschuh, Jodi, and Nist, Sherrir (2000). Learning Complex Scientific Information: Motivation Theory And its Relation to Student Perceptions, Reading \&Writing Quarterly, 16: 23-57.

3. Keller, John, M. (1987). Development and use of the ARCS model of instructional design, Journal of Instructional Development, vol. 10, no. 3.

4. Hirsch, P., Anderson, J., Colgate, J.E., Lake, J., Shwom, B., and Yarnoff C. "Enriching Freshman Design Through Collaboration with Professional Designers." Proceedings, American Society of Engineering Education national meeting, June 2002.

5. Atman, Cynthia J., Adams, Robin S. and Turns, Jennifer (2000). Using multiple methods to evaluate a freshmen design course, Proceedings of the IEEE/ASEE Frontiers in Education Conference (FIE00), Oct. 18-21, Kansas City, MO.

6. Besterfield-Sacre, M.E., Atman, C.J. \& Shuman, L.J. (1998). Engineering student attitudes assessment, Journal of Engineering Education, April, pp. 133-141.

7. Terenzini, P.T., Cabrera, A.F., Parent, J.M., \& Bjorklund, S.A. (1998). Preparing for ABET 2000: Assessment at the classroom level, Proceedings of the Annual ASEE Conference.

8. Bloom, B.S. (Ed.) (1956) Taxonomy of educational objectives: The classification of educational goals: Handbook I, cognitive domain. New York; Toronto: Longmans, Green.

\section{BIOGRAPHICAL INFORMATION}

ANN F. MCKENNA is the Director of Education Improvement in the McCormick School of Engineering and Applied Science at Northwestern University. She also holds a joint appointment as Assistant Professor in the School of Education and Social Policy and Research Assistant Professor in the Department of Mechanical Engineering. Dr. 
McKenna has extensive experience in engineering education research and curricula development and assessment. Dr. McKenna received her B.S. and M.S. degrees in Mechanical Engineering from Drexel University in

Philadelphia, Pennsylvania and a Ph.D. in Science and Mathematics Education from the University of California at Berkeley.

PENNY L. HIRSCH is Associate Director of the Writing Program at Northwestern and a Charles Deering McCormick University Distinguished Lecturer. She also has a joint appointment in the McCormick School of Engineering and Applied Science and is a principal in her own communications consulting firm. She received her B.A. in English from the University of Michigan and her M.A. and Ph.D. in English from Northwestern University. 